\title{
Differential Expression of Adhesion Molecules Shaping the T-cell Subset Prevalence during the Early Phase of Autoimmune and Trypanosoma cruzi-elicited Myocarditis
}

\author{
Ana Paula MP Marino, Maria Inês P Azevedo, Joseli Lannes-Vieira ${ }^{+}$ \\ Laboratório de Autoimunidade e Imuno-regulação, Departamento de Imunologia, Instituto Oswaldo Cruz-Fiocruz, \\ Av. Brasil 4365, 21045-900 Rio de Janeiro, RJ, Brasil
}

\begin{abstract}
The participation of cell adhesion molecules (CAMs) in the establishment of autoimmune and infectious myocarditis is an important matter of investigation and may have therapeutic implication. Trypanosoma cruzi infection induces a CD8-mediated myocarditis in patients with severe cardiomyopathy and experimental animals. Previously, we have proposed that this predominance of $C D 8^{+} T$-cells is, at least in part, consequence of the differential expression of CAMs on circulating $C D 8^{+}$lymphocytes. In the present study we investigated the participation of CAMs in shaping the phenotypic nature of the autoimmune CD4-mediated myosin-induced and the CD8-mediated T. cruzielicited myocarditis. We provide evidence that the prevalence of a certain T-cell subset inside the inflamed heart reflects the differential profile of the adhesion molecules VLA-4, LFA-1, and ICAM-1 displayed on a large proportion of this particular T-cell population in peripheral blood during the early phase of inflammation. Further, the expression of VCAM-1, ligand for VLA-4, and ICAM-1, counter-receptor for LFA-1, was up-regulated on vascular endothelium and paralleled the entrance of inflammatory cells into the cardiac tissue. Thus, this up-regulated expression of receptors-counter-receptors that regulate T-cell transmigration through the vascular endothelium may have an important role in the pathogenesis of the early phase of both autoimmune and infectious myocarditis.
\end{abstract}

Key words: Trypanosoma cruzi - myocarditis - myosin - autoimmunity - cell adhesion molecules - cell migration

During an infectious process, immunological response requires the recruitment and migration of leukocytes towards and inside a target tissue. These processes are crucial for invader control and regain homeostasis, however sometimes inflammation becomes progressive. This seems to be the case in Chagas disease-associated myocarditis, one of the leading causes of death in Latin America (Dias et al. 2002). Although the mechanisms involved in the genesis of the chronic myocarditis are very controversial, inflammatory infiltrates have crucial role in the induction of cardiac fibrosis and organ dysfunction (Cunha-Neto 2001, Tarleton 2001, Teixeira et al. 2002, Lannes-Vieira 2003). Recently, the CD8 T-cellmediated myocarditis characteristic of chronic chagasic patients with severe cardiomyopathy (Reis et al. 1993, 1997, Higuchi et al. 1997) has been successfully reproduced in $\mathrm{C} 3 \mathrm{H} / \mathrm{He}$ mice infected with the Colombian strain of Trypanosoma cruzi (dos Santos et al. 2001). Nevertheless, the molecular mechanisms determining the prevalence of $\mathrm{CD}^{+} \mathrm{T}$ lymphocytes in the cardiac tissue during T. cruzi infection remain unknown.

Migratory abilities of leukocytes are critically dependent on their nature and activation state, and

Financial supported: grants from Papes-II-Fiocruz, CNPq, Faperj, and IOC-Fiocruz, and fellowship from Capes (APMPM), IOC (MIPA), and CNPq (JLV).

${ }^{+}$Corresponding author. Fax: +55-21-2280.1589. E-mail: lannes@ioc.fiocruz.br

Received 17 January 2003

Accepted 20 August 2003 shaped by a multitude of factors including the cell adhesion molecules (CAMs) and chemokine receptors expressed on invading cells, the capacity of vascular endothelium interplay with leukocytes, and chemoattractant cytokines and extracellular matrix components expressed in target tissues (Sallusto et al. 2000, Gerard \& Rollins 2001, Moser \& Loestscher 2001, Rose et al. 2002, Thomsen et al. 2003). In this context, the requirement and functional participation of the CAMs of the integrin family LFA-1 (leukocyte function-associated antigen-1, CD1 $1 \alpha / \mathrm{CD} 18$ ) and VLA-4 (very late activation antigen-4, CD49d/CD29, $\alpha 4 \beta 1$ ) and their counter-receptors of the immunoglobulin superfamily ICAM-1 (intercellular adhesion molecule-1, CD54) and VCAM-1 (vascular cell adhesion molecule-1, CD106), respectively, in leukocyte activation and trafficking have been extensively demonstrated (Springer 1995, Sprent et al. 1997, Rose et al. 2002). Interestingly, we have shown that in the CD8mediated T. cruzi-elicited chronic myocarditis the proportional distribution of $\mathrm{CD} 4^{+}$and $\mathrm{CD} 8^{+} \mathrm{T}$-cells in the myocardium mirrors the frequency of cells expressing the LFA-1 ${ }^{\text {High }}$ VLA- ${ }^{\text {High }}$ activation phenotype among $\mathrm{CD} 4^{+}$ and $\mathrm{CD}^{+}$peripheral blood T-cells (dos Santos et al. 2001). In this context, the expression of ICAM-1 and VCAM-1 on vascular endothelium has been associated with the presence of $\mathrm{CD}^{+}$infiltrating T-cells in the cardiac tissue of chagasic patients with severe cardiomyopathy (Benvenuti et al. 2000). Recently, we have demonstrated that VLA-4/VCAM-1-pathway, but not LFA-1/ICAM-1mediated interactions, plays a pivotal role in the establishment of CD8-mediated T. cruzi-induced meningoencephalitis (Roffê et al. 2003). Altogether, these results led us to hypothesize that the predominance of 
$\mathrm{CD}^{+}$T-cells in the myocardium of $T$. cruzi-infected individuals reflects the profile of CAMs displayed by the peripheral blood CD8 ${ }^{+}$lymphocytes (dos Santos et al. 2001, Lannes-Vieira 2003). Therefore, the present study was undertaken to test whether the prevalence of a given T-cell subset in the myocardium during an inflammatory process reflects the differential profile of CAMs acquired by this particular T-cell population present in peripheral blood. For that, we assessed the expression of CAMs on peripheral blood lymphocytes during the genesis of inflammation using as experimental models the CD4mediated myosin-induced (Wang et al. 1999) and the CD8mediated T. cruzi-elicited (dos Santos et al. 2001) myocarditis. Further, considering that the endothelium of the target tissue is more than a passive partner in the interplay with leukocytes, the expression of CAMs on cardiac endothelial cells was also studied.

\section{MATERIALS AND METHODS}

Animals - All experiments were performed using female $\mathrm{C} 3 \mathrm{H} / \mathrm{He}\left(\mathrm{H}-2^{\mathrm{k}}\right)$ 5-7 weeks old obtained from the Animal Facilities, Cecal, Oswaldo Cruz Foundation (Fiocruz). The animals were maintained under standard conditions in the animal house and all the experimental procedures were conducted according to the institutional guidelines for the Fiocruz.

Parasites and experimental infection - Mice were infected intraperitoneally with 100 blood trypomastigote forms of the Colombian type III strain (Andrade 1974) of T. cruzi isolated by Federici et al. (1964) and maintained by serial passages from mice to mice in the Laboratory of Autoimmunity and Immunoregulation, IOC-Fiocruz (Rio de Janeiro, Brazil). Parasitemia was estimated using $5 \mu l$ of blood obtained from the tail vein according to Brener's method (Brener 1962), and employed as a parameter to establish acute and chronic phases. As we have previously described, circulating parasites were detected 14 days post-infection (dpi) and parasitemia peak was achieved at 42 dpi (dos Santos et al. 2001).

Induction of myosin-triggered myocarditis - To induce autoimmune myocarditis, mice were immunized with 100 $\mu \mathrm{g}$ of porcine cardiac myosin (M0531, Sigma, US), as previously described (Wang et al. 1999). Briefly, the animals were immunized with myosin emulsified in complete Freund's adjuvant (CFA) in a total volume of 0.2 $\mathrm{ml}$. Three sites in the dorsal flank received subcutaneous injections. Mice were boosted 7 days later in an identical manner, but using Freund's incomplete adjuvant. Control mice were injected with saline or adjuvant emulsion omitting myosin.

Antibodies - Specific monoclonal antibodies antiCD8 $\alpha$-FITC (clone 53-6.7), anti-CD4-PE (GK 1.5), anti-T cell receptor $\alpha \beta$-biotin (clone H57-597), anti-CD11 $\alpha$-FITC (CD11 $\alpha / \mathrm{CD} 18 \beta$ or LFA-1, clone M17/4), anti-ICAM-1biotin (CD54, clone 3E2), anti-VLA-4-biotin (CD49d, $\alpha 4$ chain, clone 9C10), anti-VCAM-1-biotin (CD106, clone 5110C9), and isotype control were purchased from PharMingen (US). Anti-F4/80 polyclonal antibody recognizing macrophages was purchased from Caltag (US). Hibridomas producing monoclonal antibodies antiMac-1 (CD11 $\beta$, clone M1/70.15.11.5.HL), anti-CD8 $\alpha$ (clone
53-6.7) and anti-CD4 (GK1.5) were purchased from the Cell Bank of the Federal University of Rio de Janeiro, expanded and the supernatants used for immunohistochemistry. Biotin-conjugated antibody recognizing rat immunoglobulins was purchased from DAKO (Denmark), peroxidase-streptavidin complex was obtained from Amersham (England) and Cy-chrome-conjugated streptavidin was purchased from PharMingen. Appropriate controls were prepared by replacing primary antibodies with purified rat immunoglobulin. Antibodies and reagents were used according to manufacturers' instructions.

Immunohistochemical characterization of inflammatory infiltrates and CAMs present in the cardiac tissue of myosin-immunized and T. cruzi-infected mice - Groups of 5-15 mice were sacrificed at 7, 14, 21 and 28 days after $T$. cruzi infection, in order to characterize the kinetic of CD8mediated myocarditis establishment, and 21 days after myosin immunization, when CD4-mediated myocarditis is established (Grässl et al. 1997, Wang et al. 1999). Groups of 3 age-matched control mice were sacrificed at the same time-points. The heart was removed, embedded in tissue freezing medium (O.C.T., Tissue Tek, Miles Laboratories, US) and stored in liquid nitrogen. The indirect immunoperoxidase technique was performed as previously described (dos Santos et al. 2001). Briefly, serial cryostat sections 5-7 $\mu \mathrm{m}$-thick were mounted on poly-L-lysincovered glass slides and fixed for $10 \mathrm{~min}$ in cold acetone. Endogenous peroxidase and non-specific antibody binding were blocked incubating the specimens with PBS containing $0.1 \%$ sodium azide and normal goat serum diluted 1/50 (Sigma). Thereafter, sequential incubations with primary antibodies (anti-cell markers, anti-CAMs or specie-matched control immunoglobulin), secondary biotinylated antibodies (goat anti-rat immunoglobulin) when required, and streptavidin-peroxidase complex were performed. All incubations were performed for $40 \mathrm{~min}$ with antibodies diluted in 1\% BSA-PBS, and were followed by washes in PBS. The peroxidase reaction was developed with 9-amino3-ethylcarbazole in the presence of hydrogen peroxide. The material was counter-stained with Mayer's haematoxylin and analyzed under a light microscope. Sections of spleen were used as positive controls for lymphocyte staining. The numbers of CD4- and CD8positive cells, ICAM-1 - and VCAM-1-expressing and total blood vessels were counted in 50 microscope fields (250X) per tissue section in three heart sections of each animal. The data were presented as mean and standard error of each group of animals.

Flow cytometry preparations and analysis - This assay was performed as previously described (dos Santos et al. 2001). Briefly, animals were sacrificed by blood removal through retro-orbital plexus puncture under anesthesia. Suspensions of blood mononuclear cells were prepared by pooling $1.5 \mathrm{ml}$ of heparinized blood ( 3 animals/ sample) and performing Fycoll Hypaque ${ }^{\mathrm{TM}}(\mathrm{d}=1.077 \mathrm{~g} / \mathrm{ml}$, Sigma) separation. In order to prepare myocardium mononuclear cell suspensions, the hearts (10-15) were washed to remove blood clots, minced with scissors in 1$2 \mathrm{~mm}$ fragments and submitted to enzymatic digestion using a solution containing $0.015 \%$ trypsin (T4799, Sigma) 
and colagenase A (103586, Boehringer Mannheim, Germany), as we have previously described (dos Santos et al. 2001). The mononuclear cells recovered were washed and resuspended in PBS containing $2 \%$ of FCS. To minimize unspecific labeling, the blockage of $\mathrm{Fc}$ receptors was performed for $30 \mathrm{~min}$ at $4^{\circ} \mathrm{C}$ with PBS containing $2 \%$ of normal mouse serum and $2 \%$ of FCS. Immunofluorescence labeling procedures involved the incubation of viable $10^{6}$ blood or $10^{5}$ heart mononuclear cells with primary antibody-biotin followed by incubation with $\mathrm{Cy}$ Chrome-streptavidin and fluorochromo-conjugated specific antibodies. Optimal concentrations of each antibody were determined in preliminary experiments. All incubations were performed for $40 \mathrm{~min}$ at $4^{\circ} \mathrm{C}$ with antibodies diluted in PBS containing $2 \%$ of FCS, and were followed by washes in a similar medium. Controls of specific labeling were prepared using isotype matched controls. Samples were fixed in cold PBS containing 1\% of formaldehyde. One-color labeled samples were prepared to set compensation values.

Flow cytometry studies were performed using a FACScalibur (FACScalibur, Becton Dickinson, CA, US). Lymphocytes were gated using a narrow forward-angle light scatter parameter to exclude dead cells from analysis. At least 12,000 cells were acquired inside this gate. Fluorescence gates were cut in accordance to labeling controls, respecting curve inflexions. Cytometric analyses were performed using the program WinMDI Version 2.5.

Statistical analysis - Arithmetic means and standard errors of the means were calculated. The Student's t-test was used to analyze the statistical meaning of the observed differences. Probability values $(p)$ of 0.05 or less were considered significant.

\section{RESULTS}

Phenotypic analysis of inflammatory mononuclear cells present in the cardiac tissue and mononuclear cells present in the peripheral blood of myosin-immunized $\mathrm{C} 3 \mathrm{H} / \mathrm{He}$ mice - Diffuse and focal inflammatory infiltrates characterize the myosin-induced myocarditis at 21 days after the first injection of antigen. The cells composing these inflammatory infiltrates were characterized using immunohistochemical assay. In comparison with the rare inflammatory cells present in the cardiac tissue of CFAinoculated mice, the more pronounced inflammatory foci present in the myocardium of myosin-immunized animals consisted predominantly of macrophages $(77.5 \%), \mathrm{CD} 4^{+}$ T-cells (17.7\%) and, to a lesser extent, CD8 ${ }^{+} \mathrm{T}$-cells (4.7\%), illustrating a CD4-mediated myocarditis (Fig. 1), as previously described (Grässl et al. 1997).

In order to test our hypothesis that the predominance of a given T-cell population in the inflamed heart is, at least in part, consequence of the differential profile of CAMs acquired by this cell subset present in peripheral blood, we investigated the activation status of circulating T-lymphocytes from myosin-immunized mice. Initially, no significant alterations were detected in the $\mathrm{CD} 4 / \mathrm{CD} 8$ ratio when myosin-immunized mice were compared with salineor CFA-injected animals (Fig. 2A). Interestingly, a remarkable increase in the proportion of VLA $-4^{+}$cells was observed in the peripheral blood of myosin-immunized

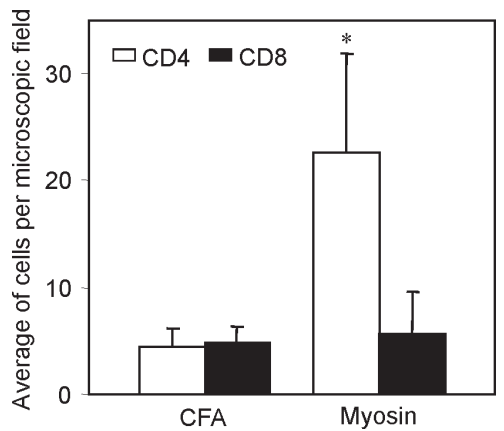

Fig. 1: phenotypic analysis of inflammatory infiltrates present in the cardiac tissue of $\mathrm{C} 3 \mathrm{H} / \mathrm{He}$ mice immunized with myosin. The immunohistochemical analysis was performed at 21 days after the first immunization. The numbers of $\mathrm{CD}^{+}$and $\mathrm{CD} 8^{+}$lymphocytes were counted as described in Materials and Methods. Each experimental group consisted of 5 mice; * indicates statistically significant data $(p<0.05)$

mice at 21 days after the first injection of antigen, when compared with saline- or CFA-inoculated animals (Fig. 2B). To test our hypothesis, the proportions of $\mathrm{CD} 4^{+}$and $\mathrm{CD} 8^{+}$ among VLA $-4^{+}$cells were analyzed. As predicted, a significant increase in the proportion of $\mathrm{VLA}-4^{+} \mathrm{CD} 4^{+}$ peripheral blood T-cells was restricted to myosin-immunized mice in comparison with saline- or CFA-injected animals. Furthermore, the alteration of VLA-4 expression was restricted to the $\mathrm{CD} 4^{+} \mathrm{T}$-cells, whereas the proportion of VLA $-4^{+} \mathrm{CD} 8^{+}$remained unaltered (Fig. 2B-C). LFA-1 expression was also distinctly altered on peripheral blood mononuclear cells and accompanied the formation of CD4mediated myocarditis (data not shown).

Phenotypic analysis of inflammatory mononuclear cells present in the cardiac tissue and peripheral blood of Colombian-infected $\mathrm{C} 3 \mathrm{H} / \mathrm{He}$ mice - Histopathological studies showed that mononuclear cells forming a diffuse inflammatory process were firstly detected in the cardiac tissue of the Colombian-infected $\mathrm{C} 3 \mathrm{H} / \mathrm{He}$ mice at $14 \mathrm{dpi}$. These rare inflammatory cells were VLA- $4^{+}$(Fig. 3A). Also, during the early acute infection (21-28 dpi), the majority of mononuclear cells infiltrating the cardiac tissue were VLA- $4^{+}$activated cells (Fig. 3A) and expressed Mac-1 (data not shown). The cytofluorimetric analysis of the invading cells enzymatically harvested from the cardiac tissue of T. cruzi-infected animals at 28 dpi showed that almost all of them are VLA- $4^{+}$and LFA- $1^{+}$(Fig. 3B). Further, the inflammatory infiltrates at this time point are composed mainly of $\mathrm{CD} 8^{+}$lymphocytes and, to a lesser extent, $\mathrm{CD} 4^{+}$ cells (Fig. 3C) and macrophages (data not shown), showing that the establishment of the CD8-mediated myocarditis is an early event during $T$. cruzi infection. In the cardiac tissue of non-infected controls the rare mononuclear cells consisted mainly of $\mathrm{CD}^{+}$, as we have previously shown (dos Santos et al. 2001). Additionally, cytofluorimetric analysis revealed that both $\mathrm{CD} 4$ and $\mathrm{CD} 8$ cell subsets from the cardiac tissue express T cell receptor (data not shown) and confirmed that almost all of these Tcells are VLA- $4^{+}$(Fig. 3C). Therefore, the majority of CD4 ${ }^{+}$ and $\mathrm{CD}^{+}$cells isolated from the heart of T. cruzi-infected mice were activated, bearing VLA-4 and LFA-1. 
A

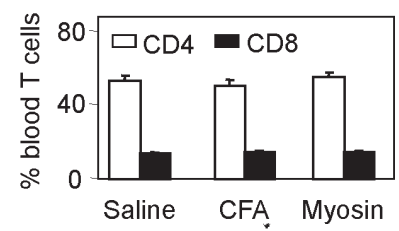

B
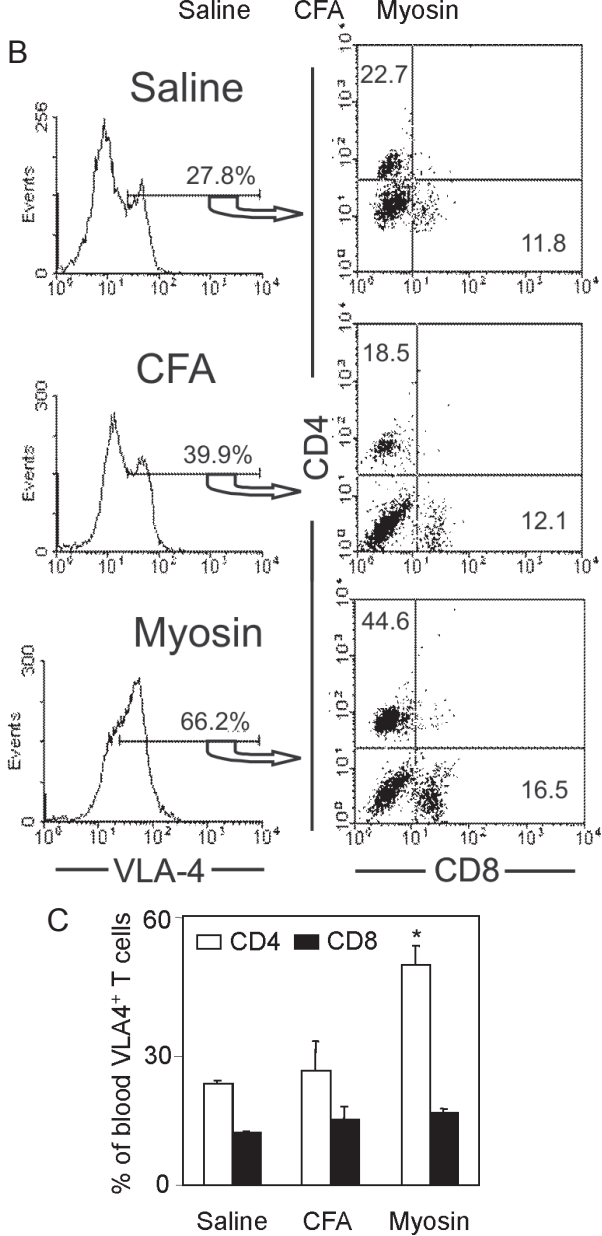

Fig. 2: cytofluorimetric evaluation revealed - A: a similar percentage of $\mathrm{CD}^{+}$and $\mathrm{CD} 8^{+} \mathrm{T}$-cells in peripheral blood of animals injected with saline, CFA and CFA-myosin; B: an increased proportion of VLA $-4^{+}$cells in peripheral blood of myosin-immunized mice in comparison with saline- or CFA-injected animals. The analysis of $\mathrm{CD}^{+}$and $\mathrm{CD} 8^{+}$T-cell subsets among VLA- $4^{+}$population showed that a significant increase in the proportion of $\mathrm{VLA}-4^{+} \mathrm{CD} 4^{+}$was restricted to myosin-immunized mice; $\mathrm{C}$ : statistical analysis confirmed a significant increase in the percentage of peripheral blood VLA $-4^{+} \mathrm{CD} 4^{+}$cells in myosin-immunized mice compared with CFA-injected animals. Each experimental group consisted of 3-5 mice; * indicates statistically significant data $(p<0.05)$.

Trying to test our hypothesis that the predominance of $\mathrm{CD}^{+} \mathrm{T}$-cells in the inflamed heart of T. cruzi-infected mice is, at least in part, consequence of the differential profile of CAMs acquired by this T-cell subset present in peripheral blood, we analyzed the expression of CAMs on circulating T-cells. A remarkable up-regulation of VLA4 expression was observed on circulating mononuclear cells at $28 \mathrm{dpi}$ (Fig. 3D). As predicted, most of these VLA$4^{+}$cells were $\mathrm{CD}^{+}$, while a minor proportion of $\mathrm{VLA}-4^{+}$ cells were $\mathrm{CD}^{+}$, in contrast with what is observed in noninfected controls (Fig. 3D).
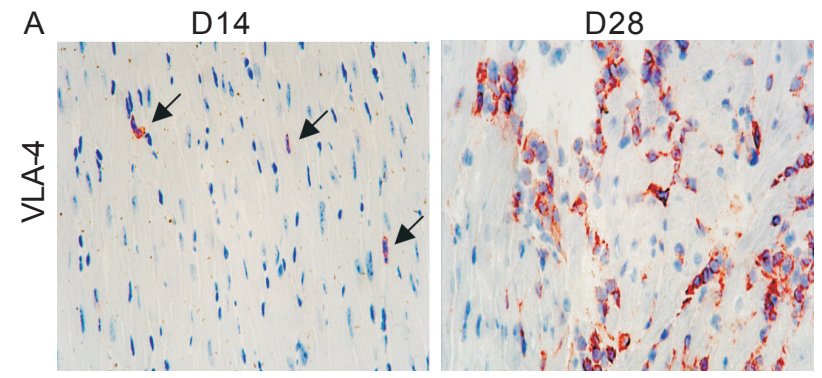

B
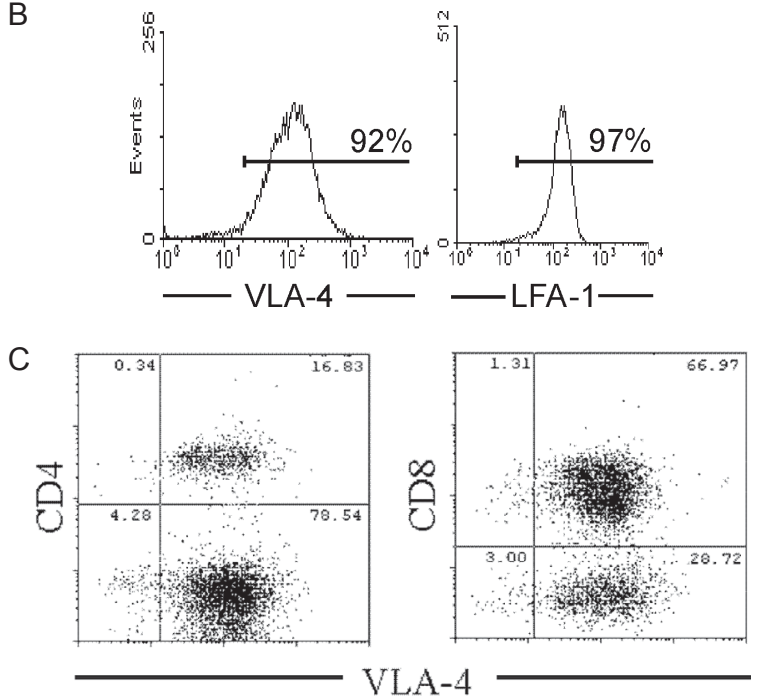

D
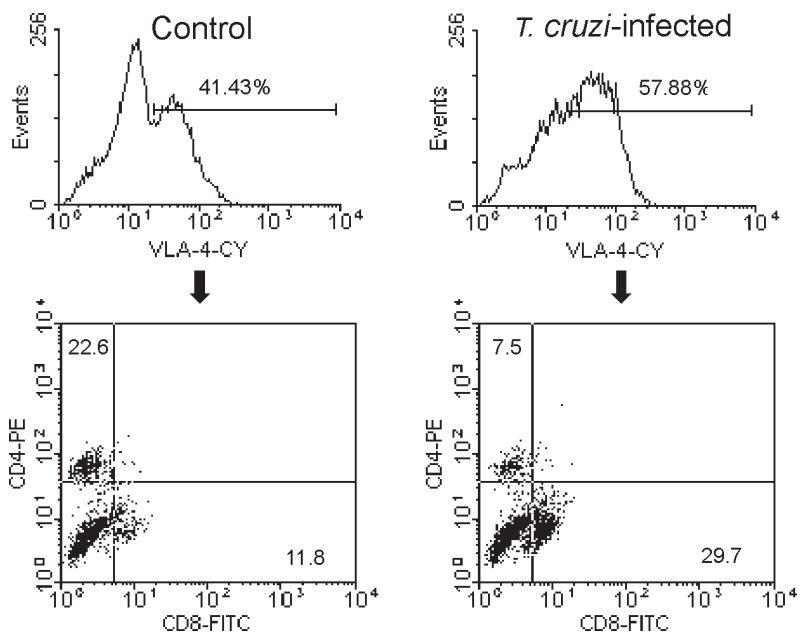

Fig. 3: phenotypic analysis of inflammatory infiltrates present in the cardiac tissue and peripheral blood mononuclear cells of Trypanosoma cruzi-infected $\mathrm{C} 3 \mathrm{H} / \mathrm{He}$ mice - A: VLA-4 ${ }^{+}$cells were immunohistochemically detected in the heart tissue of T. cruziinfected mice at 14 and 28 days post-infection, 400X; B: cytofluorimetric analysis of mononuclear cells enzymatically harvested from cardiac tissue showed that at $28 \mathrm{dpi}$ most of the inflammatory cells are VLA $-4^{+}$and LFA $-1^{+}$cells; C: the majority of VLA $-4^{+}$mononuclear cells are $\mathrm{CD} 8^{+} \mathrm{T}-$ lymphocytes and most of the $\mathrm{CD}^{+}$and $\mathrm{CD}^{+}{ }^{+}$-cells present in the heart tissue at $28 \mathrm{dpi}$ are activated; D: cytofluorimetric analysis of peripheral blood mononuclear cells showed an increase in the percentage of VLA- $4^{+}$ cells at $28 \mathrm{dpi}$, when compared with control non-infected animals. Most of the VLA- $4^{+}$cells are $\mathrm{CD} 4^{+} \mathrm{T}$ lymphocytes in non-infected mice and $\mathrm{CD} 8^{+} \mathrm{T}$-cells in $T$. cruzi-infected animals. Each experimental group consisted of 10-15 mice. The flow cytometric profiles are representative results of the group analyzed. 
Previously, we have reported that during chronic $T$. cruzi infection a large proportion of $\mathrm{CD} 8^{+}$peripheral blood T-cells is activated, while only a minor subset of $\mathrm{CD} 4^{+}$ circulating T lymphocytes bears activation markers (dos Santos et al. 2001). To draw a similar analysis, the profile of CAMs expressed by peripheral blood $\mathrm{CD}^{+}$and $\mathrm{CD} 8^{+}$ T-cells from T. cruzi-infected mice at 28 dpi was studied. The results showed that also during the early acute phase the majority of $\mathrm{CD}^{+} \mathrm{T}$-cells are VLA- $4^{+}$, while a minority of $\mathrm{CD}^{+}$lymphocytes express VLA-4 (Fig. 4A). A kinetic study demonstrated that the initial alteration of VLA-4, LFA-1 and ICAM-1 expression on circulating mononuclear cells paralleled the entrance of the first inflammatory cells inside the cardiac tissue, occurring at $14 \mathrm{dpi}$ (Fig. 4B). The analysis of the profile of CAMs on $\mathrm{CD}^{+}$and $\mathrm{CD} 8^{+} \mathrm{T}$ cells present in the peripheral blood of non-infected
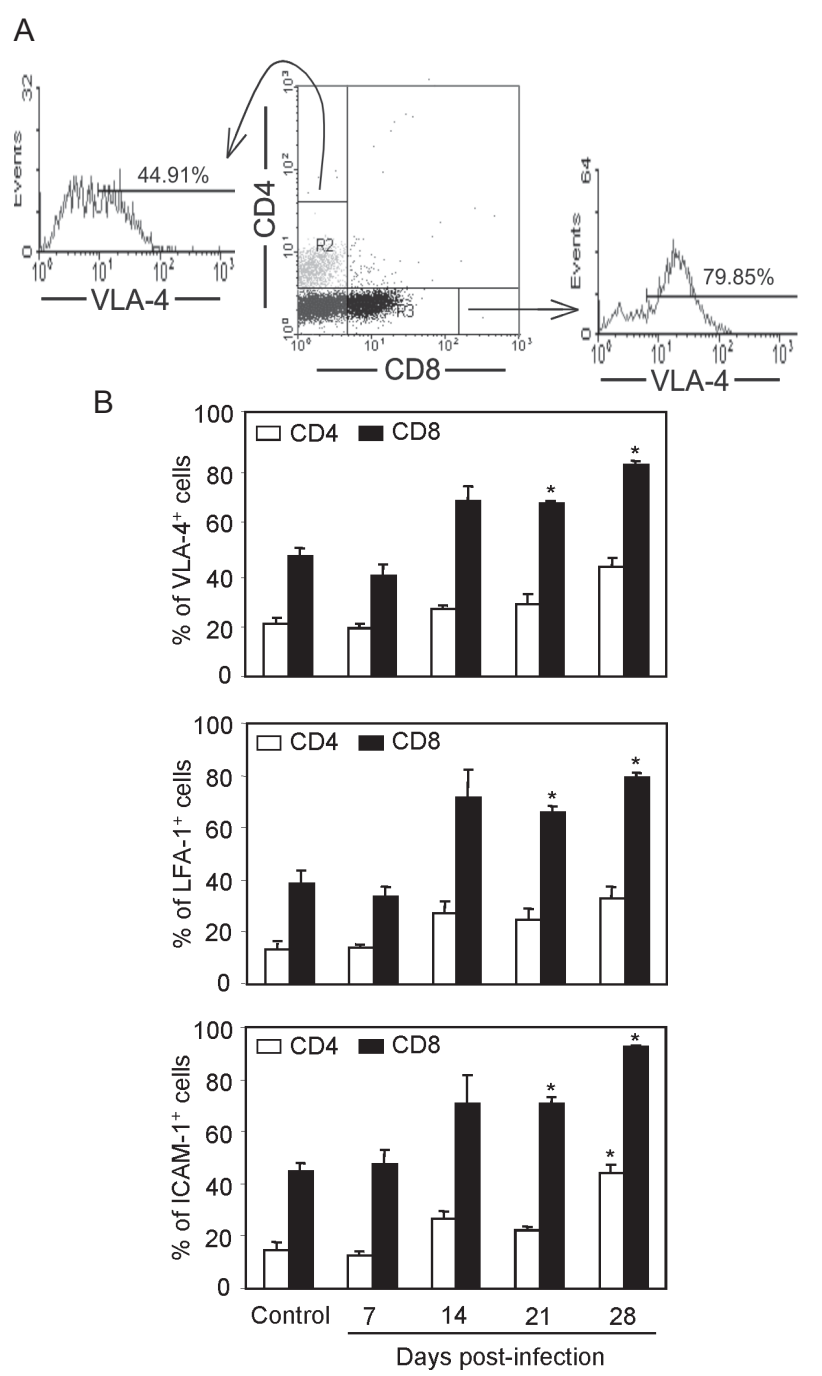

Fig. 4A: flow cytometric analysis of mononuclear cells obtained from peripheral blood of Trypanosoma cruzi-infected mice at 28 dpi showed that most of $\mathrm{CD}^{+}$cells are VLA- $4^{+}$, while a minor population of $\mathrm{CD}^{+}$lymphocytes express VLA-4; B: flow cytometric analysis of mononuclear cells obtained from peripheral blood of control and $T$. cruzi-infected $\mathrm{C} 3 \mathrm{H} / \mathrm{He}$ mice (7-28 dpi) showing the percentage of VLA $-4^{+}$, LFA- $1^{+}$and ICAM- $1^{+}$cells among the CD $4^{+}$ and $\mathrm{CD}^{+}$lymphocytes. Each experimental group consisted of 912 mice; * indicates statistically significant data $(p<0.05)$. controls showed that a large proportion of $\mathrm{CD}^{+} \mathrm{T}$-cells express VLA-4, LFA-1 and ICAM-1, while a minor proportion of circulating $\mathrm{CD} 4^{+} \mathrm{T}$-cells express these CAMs. Similar profiles were found in the peripheral blood of $T$. cruzi-infected mice, however a remarkable increase in the proportion of $\mathrm{CD} 8^{+} \mathrm{T}$-cells bearing VLA-4, LFA-1, and ICAM-1 was observed after 14 dpi (Fig. 4B). Altogether, these results show that the increase in the proportion of $\mathrm{CD} 8{ }^{+} \mathrm{T}$-cells expressing VLA-4, LFA-1, and ICAM-1 occurs during the early acute phase and parallels the establishment of the CD8-mediated T. cruzi-elicited myocarditis.

Expression of CAMs on the cardiac vascular endothelium of Colombian-infected $\mathrm{C} 3 \mathrm{H} / \mathrm{He}$ mice - To further study the molecules involved in the interplay with leukocytes and putatively involved in the transendothelial migration of these cells into the cardiac tissue, we carried out an immunohistochemical study analyzing the expression of VCAM-1, ligand for VLA-4, and ICAM-1, counter-receptor for LFA-1 and Mac-1, on heart cryopreserved sections. The vascular endothelial cells of the cardiac tissue of control mice do not express or only small numbers of blood vessels present dull expression of VCAM-1 (Fig. 5A-B). Slight up-regulation of VCAM-1 and ICAM-1 on cardiac endothelial cells was observed since day 14 post-infection (data not shown). A remarkable increase in the numbers of VCAM- $1^{+}$and ICAM- $1^{+}$blood vessels was observed in the cardiac tissue of T. cruziinfected mice on day 28 post-infection (Fig. 5A). Moreover, the increase in the proportion of VCAM- $1^{+}$ and ICAM $-1^{+}$blood vessels was accompanied by an upregulation of these molecules on the cardiac endothelium of T. cruzi-infected mice (Fig. 5B). In contrast to VCAM-1 expression that was restricted to the endothelium of cardiac blood vessels, the expression of ICAM-1 was more widespread, being also detected and strongly up-regulated on the sarcolemma of cardiomyocytes and on invading mononuclear cells (Fig. 5B).

\section{DISCUSSION}

In the present study, we provide evidence that the predominance of a given T-cell subpopulation inside the inflamed cardiac tissue in an autoimmune or infectious situation reflects the differential profile of the cell adhesion molecules VLA-4, LFA-1 and ICAM-1 displayed by this particular T-cell subset present in peripheral blood. Moreover, we show that the cardiac tissue must be permissive to the entrance of these activated cells, being this state reflected, at least in part, by the expression of VCAM-1 and ICAM-1 on vascular endothelium.

Immunization with cardiac myosin causes $\mathrm{CD} 4^{+} \mathrm{T}$ cellmediated acute self-resolving myocarditis in genetically predisposed $\mathrm{C} 3 \mathrm{H} / \mathrm{He}$ mice and serves as a model for autoimmune heart disease (Pummerer et al. 1996, Grässl et al. 1997, Wang et al. 1999). Herein, we show that the myosin-induced CD4-mediated myocarditis is associated with differential expression of VLA-4 and LFA-1 on circulating $\mathrm{CD}^{+}{ }^{-} \mathrm{T}$ lymphocytes, supporting our hypothesis that the differential profile of CAMs expressed by $\mathrm{CD}^{+}{ }^{+} \mathrm{T}$-cells is, at least in part, determinant of their migration into the heart tissue. Comparable association 

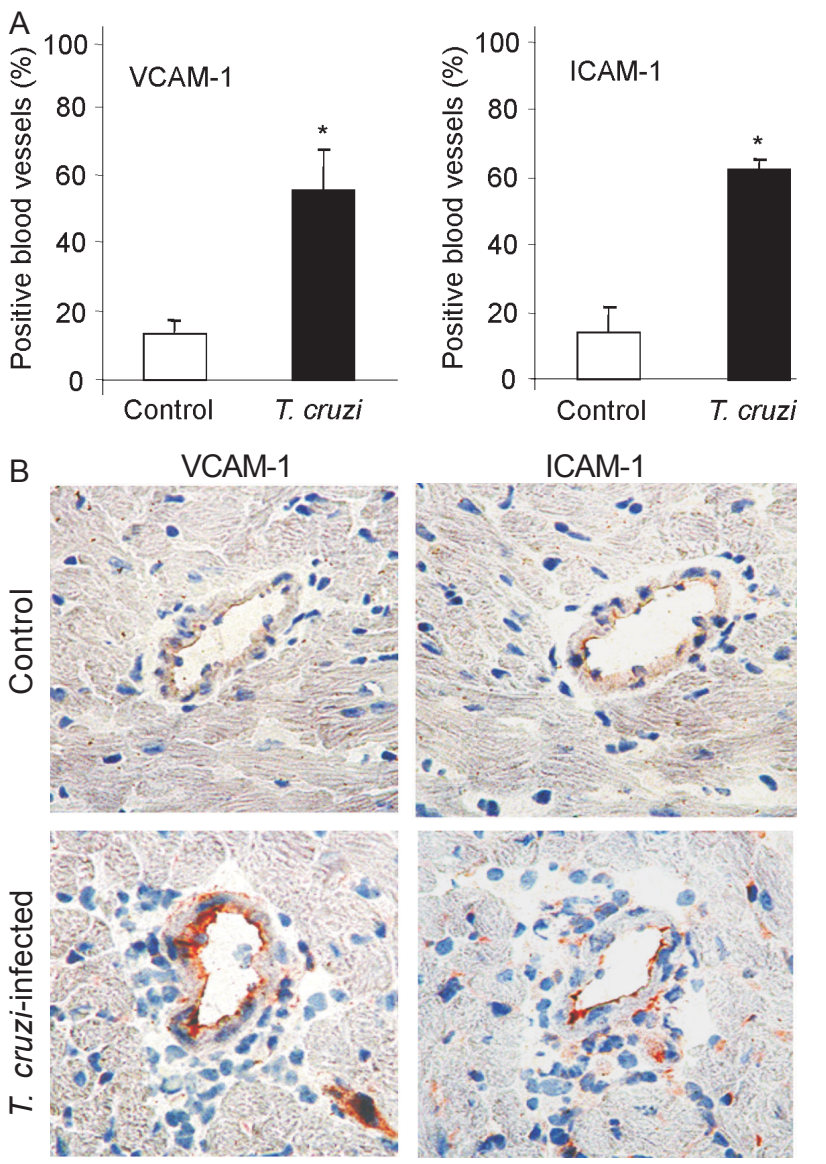

Fig. 5: immunohistochemical analysis of $\mathrm{VCAM}^{-} 1^{+}$and ICAM-1 ${ }^{+}$ blood vessels present in the cardiac tissue of control non-infected and Trypanosoma cruzi-infected $\mathrm{C} 3 \mathrm{H} / \mathrm{He}$ mice (28 dpi) - A: percentage of blood vessels bearing VCAM-1 and ICAM-1; B: immunohistochemical analysis showed up-regulation of VCAM-1 and ICAM-1 expression on cardiac vascular endothelium of T. cruziinfected mice when compared with control animals, 400X; ICAM1 expression was also detected on cardiomyocytes and invading mononuclear cells present in the cardiac tissue of infected mice. These results represent three replica experiments. Each experimental group consisted of 3-5 mice; * indicates statistically significant data $(p<0.05)$.

was observed in the CD8-mediated T. cruzi-elicited myocarditis given that a large proportion of peripheral blood $\mathrm{CD} 8^{+} \mathrm{T}$-cells, but not of $\mathrm{CD} 4^{+}$lymphocytes, displays differential profile of VLA-4, LFA-1 and ICAM1. In agreement with these data is the demonstration that during chronic infection the predominance of $\mathrm{CD} 8^{+} \mathrm{T}$ cells in the cardiac tissue is not only consequence of the passive influx of the predominant cell population in the immune compartments (blood and lymphoid tissues), where the majority of T-cells are $\mathrm{CD}^{+}$, but reflects the activation phenotype (CD62L Low/-, LFA- ${ }^{\text {High }}$, and VLA$4^{\mathrm{High}}$ ) exhibited by the majority of $\mathrm{CD} 8^{+}$peripheral blood T-cells, while a minor population of the circulating $\mathrm{CD}^{+}$ cells bears these activated markers (dos Santos et al. 2001). In this context, a recent study has demonstrated that patients with a mild form of chagasic myocarditis present a lower percentage of $\mathrm{CD} 3^{+} \mathrm{VLA}-4^{+}$peripheral blood cells, in comparison with those with severe chronic cardiomyopathy (Laucella et al. 2001). Interestingly, high frequency of activated $\mathrm{CD}^{+} \mathrm{T}$ lymphocytes has also been observed in the blood of cardiac chagasic patients (Dutra et al. 1996). Further, we bring evidence that the differential activation state of the $\mathrm{CD} 8^{+} \mathrm{T}$-cells in $T$. cruzi-infected mice observed during the chronic phase (dos Santos et al. 2001) is acquired early during the acute infection. In fact, during the acute T. cruzi infection drastic immunological abnormalities are observed, including polyclonal activation in murine as well as leukocytosis and lymphocytosis (mainly due to CD8 T-cell subset enhancement) in non-human primate models for Chagas disease (D'Imperio Lima et al. 1985, Bonecini-Almeida 2000). Thus, it is tempting to speculate that the increased availability of activated peripheral blood $\mathrm{CD}^{+} \mathrm{T}$-cells in T. cruzi-infected individuals may contribute to the establishment and perpetuation of the CD8-mediated myocarditis.

The mechanisms triggering the differential activation of $\mathrm{CD}^{+}$lymphocytes in myosin-immunized and $\mathrm{CD}^{+} \mathrm{T}$ cells in T. cruzi-infected individuals are not clear, however one should consider that the nature of the administered antigen (soluble antigen emulsified in CFA) or infectious agent (an intracellular parasite) may explain the distinct antigen presentation and cell activation in these models. As consequence, a differential influx of $\mathrm{CD}^{+}$and $\mathrm{CD} 8^{+}$ $\mathrm{T}$-cells into circulation and from this into permissive target tissues should be expected in the two distinct models.

The importance of VCAM-1 and ICAM-1 in controlling cell adhesion and migration is well established (Springer 1995, Sprent et al. 1997). In this context, it has been shown that expression of endothelial ICAM-1 is a prerequisite for target organ recognition by autoreactive T-cells in the model for CD4-mediated myocarditis studied here (Pummerer et al. 1996). In addition, VCAM-1 expression was demonstrated in mice that developed myosin-induced CD4-mediated myocarditis (Wang et al. 1999). Consistently, up-regulation of VCAM-1 expression was observed since the early acute $T$. cruzi infection and paralleled the presence of VLA $-4^{+}$activated mononuclear cells in the cardiac tissue. Besides that, ICAM-1 expression that was dull on endothelial cells of cardiac tissue of non-infected animals was also up-regulated in infected mice. Recently, we have shown that during the chronic T. cruzi infection a remarkable increase in the expression of VCAM-1 was observed on cardiac vascular endothelium (dos Santos et al. 2001), as found in Coxsackievirus B3-induced myocarditis (Seko et al. 1996). Most importantly, ICAM$1^{+}$and VCAM- $1^{+}$blood vessels associated with $\mathrm{CD} 8^{+}$ infiltrating T-cells were also detected in the cardiac tissue of chagasic patients with severe cardiomyopathy (Benvenuti et al. 2000). Altogether, these findings strongly suggest that VLA-4/VCAM-1 and LFA-1/ICAM-1 interactions could contribute to the attachment of circulating $\mathrm{CD}^{+}$and $\mathrm{CD} 8^{+} \mathrm{T}$-cells to activated endothelium leading to migration of these cells, depending on their differential activation profile, into the cardiac tissue in myosin-immunized and T. cruzi-infected mice, resulting in CD4-mediated and CD8-mediated myocarditis, respectively. 
Local and systemically produced pro-inflammatory cytokines may modulate the expression of ICAM-1 and VCAM-1 on endothelial cells (Thomsen et al. 2003). In fact, ICAM-1 expression on cardiac vascular endothelial of myosin-immunized mice was shown to be dependent on TNF- $\alpha$ expression (Pummerer et al. 1996). The proinflammatory cytokines IL-12, IFN- $\gamma$ and TNF- $\alpha$ were shown to be synthesized inside the cardiac tissue of $T$. cruzi-infected humans and mice (Reis et al. 1997, Talvani et al. 2000, dos Santos et al. 2001). Thus, these proinflammatory cytokines could modulate the expression of CAMs on vascular endothelium of the inflamed heart of T. cruzi-infected individuals and hence promote cellular infiltration of leukocytes into this target tissue. In fact, this possibility was supported by the results showing that the decreased myocarditis observed in IFN- $\gamma$ immunodeficient mice infected with T. cruzi (Aliberti et al. 2001) paralleled the diminished expression of VCAM-1 and ICAM-1 on cardiac endothelial cells (Michailowisky pers. commun.).

Another interesting point concerns the finding that most of the $\mathrm{CD}^{+}$and $\mathrm{CD} 8^{+} \mathrm{T}$-cells present in the inflamed myocardium of acutely $T$. cruzi-infected mice present the VLA $-4^{+}$activated phenotype. Mononuclear cells expressing VLA-4 (ligand for VCAM-1 as well as a receptor for fibronectin) and CD44 (receptor for fibronectin and hyaluronic acid) were detected in the myocardium of chronic chagasic patients (Reis et al. 1993). T. cruziinfected humans and experimental animals present extracellular matrix abnormalities that parallel heart inflammation and dysfunction (Andrade et al. 1989, Higuchi et al. 1999). In this context, we have shown that in T. cruziinfected $\mathrm{C} 3 \mathrm{H} / \mathrm{He}$ mice, a fine fibronectin network involving VLA $-4^{+}$T lymphocytes is present in the perivascular space of cardiac blood vessels during acute (Marino et al. 2003) and chronic infection (dos Santos et al. 2001), suggesting that these inflammatory cells are activated and able to interact with the extracellular matrix components in the target tissue. Thus, the interaction of VLA $-4^{+}$invading cells with extracellular matrix components, proposed to contribute to cell anchorage and activation as well as cytokine retention (Vaday et al. 2001), may play a key role in the establishment and perpetuation of T. cruzi-elicited myocarditis. Further, in the present study, we show that the majority of $\mathrm{CD}^{+}$and $\mathrm{CD} 4^{+} \mathrm{T}$-cells present in the inflamed heart tissue of Colombian-infected $\mathrm{C} 3 \mathrm{H} / \mathrm{He}$ mice during the early acute phase are LFA- $1^{+}$, as previously detected during the chronic infection (dos Santos et al. 2001). In agreement with our results, previous report has shown that LFA $-1^{+}$mononuclear cells are present in the inflamed myocardium of chronic chagasic patients with severe cardiomyopathy (Reis et al. 1993), suggesting that at least part of these inflammatory cells are activated. Further, we bring evidence that the myocytes present enhanced ICAM-1 expression, confirming a previous report (Laucella et al. 1996). Furthermore, as LFA-1/ICAM1 interactions play a crucial role forming the immunological synapse (Camacho et al. 2001), ICAM- $1^{+}$myocytes could be targets for LFA- $1^{+}$cytotoxic T-cells, contributing to heart dysfunction. As ICAM-1 expression was upregulated on heart invading mononuclear cells, one could consider that ICAM-1/LFA-1 and/or ICAM-1/Mac-1 (CR3, CD11b/CD18) interactions may also be crucial for lymphocyte-lymphocyte or lymphocyte-antigen presenting cell interplay. Therefore, the presence of VLA- $4^{+}$, LFA- $1^{+}$and ICAM- $1^{+}$mononuclear cells in the cardiac tissue of infected animals since early acute $T$. cruzi infection suggest the participation of these molecules in the migration and accumulation of inflammatory cells into this target tissue during chagasic infection. Moreover, VLA-4-, LFA-1- and ICAM-1-mediated interactions could also participate in the persistence of cell activation within the inflamed tissue via direct interaction with their ligands on myocytes, antigen presenting cells, lymphocytes or extracellular matrix components, leading to effector functions such as cytotoxicity, and release of soluble inflammatory mediators as cytokines and chemokines. Further studies are required to clarify the differential contribution of CAM-mediated interactions in parasite control and pathogenesis of the myocardial cell damage during $T$. cruzi infection.

Lastly, immunomodulators able to down-regulate the expression of CAMs on activated lymphocytes or monoclonal antibodies and antagonists specific for CAMs are being proposed and successfully used to ameliorate inflammatory processes (Yusuf-Makagiansar et al. 2002). Therefore, our results strongly supporting that VLA-4/ VCAM-1- and LFA-1/ICAM-1-mediated interactions are putatively involved in the genesis of myosin-induced and T. cruzi-elicited myocarditis point to the possibility that adhesion molecules may constitute logic targets aiming to ameliorate the prognostic of autoimmune and infectious myocarditis.

\section{ACKNOWLEDGMENTS}

To Ms Heloisa Diniz and Mr Rodrigo Mexas for preparing the figures and Ms Marta Santiago for helping with the FACS analysis.

\section{REFERENCES}

Aliberti JC, Souto JT, Marino AP, Lannes-Vieira J, Teixeira MM, Farber J, Gazzinelli RT, Silva JS 2001. Modulation of chemokine production and inflammatory responses in interferon-gamma- and tumor necrosis factor-R1-deficient mice during Trypanosoma cruzi infection. Am J Pathol 158: 1433-1440.

Andrade SG 1974. Caracterização de cepas do Trypanosoma cruzi isoladas no Recôncavo Baiano. Rev Pat Trop 3: 65121.

Andrade SG, Grimaud JA, Stocker-Guerret S 1989. Sequential changes of the connective matrix components of the myocardium (fibronectin and laminin) and evolution of the cardiac fibrosis in mice infected with Trypanosoma cruzi. Am J Trop Med Hyg 40: 252-260.

Benvenuti LA, Higuchi ML, Reis MM 2000. Upregulation of adhesion molecules and class I HLA in the myocardium of chronic chagasic cardiomyopathy and heart allograft rejection, but not in dilated cardiomyopathy. Cardiovasc Pathol 9: 111-117.

Bonecini-Almeida MG 2000. Modelos animais para o estudo in vivo da doença de Chagas e de seus aspectos histopatológicos. Macacos. In TC Araújo-Jorge, SL de Castro (eds), Doença de Chagas: Manual de Experimentação Animal, Fiocruz, Rio de Janeiro, p. 134-174. 
Brener Z 1962. Therapeutic activity and criterion of cure on mice experimentally infected with Trypanosoma cruzi. Rev Inst Med Trop São Paulo 4: 389-396.

Camacho SA, Heath WR, Carbone FR, Sarvetnick N, LeBon A, Karlsson L, Peterson PA, Webb SR 2001. A key role for ICAM-1 in generating effector cells mediating inflammatory responses. Nat Immunol 2: 523-529.

Cunha-Neto E 2001. Immunopathogenic aspects of Chagas' heart disease or "Understanding the pathogenesis of Chagas' disease cardiomyopathy towards the end of the millennium". 1st Virtual Congress of Cardiology. http://www.fac.org.ar/ cvirtual/cvirteng/cienteng/eceng/ecc4501i/icunha.htm)

D’Império Lima MR, Joskowicz M, Coutinho A, Kipnis T, Eisen H 1985. Very large and isotypically atypical polyclonal plague-forming cell responses in mice infected with Trypanosoma cruzi. Eur J Immunol 15: 201-203.

Dias JCP, Silveira AC, Schofield CJ 2002. The impact of Chagas disease control in Latin America. Mem Inst Oswaldo Cruz 97: 603-612.

dos Santos PVA, Roffê E, Santiago HC, Torres RA, Marino APMP, Paiva CN, Silva AA, Gazzinelli RT, Lannes-Vieira $\mathrm{J} 2001$. Prevalence of $\mathrm{CD}^{+} \alpha$ T-cells in Trypanosoma cruzielicited myocarditis is associated with acquisition of CD62LLowLFA-1HighVLA-4High activation phenotype and expression of IFN- $\gamma$-inducible adhesion and chemoattractant molecules. Microbes Infect 3: 971-984.

Dutra WO, Martins-Filho OA, Cançado JR, Pinto-Dias JC, Brener Z, Gazzinelli G, Carvalho JF, Cooley DG 1996. Chagasic patients lack CD28 expression on many of their circulating T lymphocytes. Scand J Immunol 43: 88-93.

Federici EE, Abelmann WH, Neva FA 1964. Chronic and progressive myocarditis in $\mathrm{C} 3 \mathrm{H}$ mice infected with Trypanosoma cruzi. Am J Trop Med Hyg 13: 272-280.

Gerard C, Rollins BJ 2001. Chemokines and disease. Nat Immunol 2: 108-115.

Grässl G, Pummerer CL, Horak I, Neu N 1997. Induction of autoimmune myocarditis in interleukin-2-deficient mice. Circulation 95: 1773-1776.

Higuchi ML, Reis MM, Aiello VD, Benvenuti LA, Gutierrez PS, Bellotti G, Pileggi F 1997. Association of an increase in $\mathrm{CD}^{+} \mathrm{T}$ cells with the presence of Trypanosoma cruzi antigens in chronic, human chagasic myocarditis. Am J Trop Med Hyg 56: 485-489.

Higuchi ML, Fukasawa S, De Brito T, Parzianello LC, Bellotti G, Ramires JA 1999. Different microcirculatory and interstitial matrix patterns in idiopathic dilated cardiomyopathy and Chagas' disease: a three dimensional confocal microscopy study. Heart 82: 279-85.

Lannes-Vieira J 2003. Trypanosoma cruzi-elicited CD8 ${ }^{+}$? T cellmediated myocarditis: chemokine receptors and adhesion molecules as potential therapeutic targets to control chronic inflammation? Mem Inst Oswaldo Cruz 98: 299-304.

Laucella SA, Riarte A, Prado N, Zapata J, Segura EL 2001. $\alpha 4$ integrins and sialyl Lewis x modulation in chronic Chagas disease: further evidence of persistent immune activation. Scand J Immunol 53: 514-519.

Laucella S, Salcedo R, Castaños-Velez E, Riarte A, De Titto EH, Patarroyo M, Örn A, Rottenberg ME 1996. Increased expression and secretion of ICAM-1 during experimental infection with Trypanosoma cruzi. Parasite Immunol 18: 227-239.

Marino APMP, Silva AA, Pinho RT, Lannes-Vieira J 2003. Trypanosoma cruzi infection: a continuous invader-host cell cross talk with participation of extracellular matrix, and adhesion and chemoattractant molecules. Braz J Med Biol Res 36: 1121-1133.
Moser B, Loestscher P 2001. Lymphocyte traffic control by chemokines. Nat Immunol 2: 123-128.

Pummerer CL, Grassl G, Sailer M, Bachmaier KW, Penninger JM, Neu N 1996. Cardiac myosin-induced myocarditis: target recognition by autoreactive $\mathrm{T}$ cells requires prior activation of cardiac interstitial cells. Lab Invest 74: 845852.

Reis DD, Jones EM, Tostes Jr S, Lopes ER, Gazzinelli G, Colley DG, Mc Curley TL 1993. Characterization of inflammatory infiltrates in chronic chagasic myocardial lesions: presence of tumor necrosis factor- $\alpha^{+}$cells and dominance of granzyme $\mathrm{A}^{+} \mathrm{CD}^{+}$lymphocytes. Am J Trop Med Hyg 48: 637-644.

Reis MM, Higuchi ML, Benvenuti LA, Aiello VD, Gutierrez PS, Bellotti G, Pileggi F 1997. An in situ quantitative immunohistochemical study of cytokines and IL-2R $\mathrm{R}^{+}$in chronic human chagasic myocarditis: correlation with the presence of myocardial Trypanosoma cruzi antigens. Clin Immunol Immunopath 83: 165-172.

Roffê E, Silva AA, Marino APMP, dos Santos PVA, LannesVieira J 2003. Essential role of VLA-4/VCAM-1 pathway in the establishment of $\mathrm{CD}^{+} \mathrm{T}$ cell-mediated Trypanosoma cruzi-elicited meningoencephalitis. J Neuroimmunol 142: 17-30.

Rose DM, Han J, Ginsberg MH 2002. $\alpha 4$ integrins and the immune response. Immunol Rev 186: 118-124.

Sallusto F, Mackay CR, Lanzavechia A 2000. The role of chemokine receptors in primary, effector, and memory immune responses. Annu Rev Immunol 18: 593-620.

Seko Y, Yagita H, Okumura K, Yazaki Y 1996. Expression of vascular cell adhesion molecule-1 in murine hearts with acute myocarditis caused by coxsackievirus B3. J Pathol 180: 450-454.

Sprent J, Thougn DF, Sun S 1997. Factors controlling the turnover of T memory cells. Immunol Rev 156: 79-85.

Springer TA 1995. Traffic signals on endothelium for lymphocyte recirculation and leukocyte migration. Annu Rev Physiol 57: 827-872.

Talvani A, Ribeiro CS, Aliberti JCS, Michailowsky V, Santos PVA, Murta SMF, Romanha AJ, Almeida IC, Farber J, Lannes-Vieira J, Silva JS, Gazzineli RT 2000. Kinetics of cytokine gene expression in experimental chagasic cardiomyopathy: tissue parasitism and endogenous IFN- $\gamma$ as important determinants of chemokine mRNA expression during infection with Trypanosoma cruzi. Microbes Infect 2: $851-866$.

Tarleton RL 2001. Parasite persistence in the aetiology of Chagas' disease. Int J Parasitol 31: 549-553.

Teixeira MM, Gazzinelli RT, Silva JS 2002. Chemokines, inflammation and Trypanosoma cruzi infection. Trends Immunol 18: 262-265.

Thomsen AR, Nansen A, Madsen AN, Bartholdy C, Christensen JP 2003. Regulation of T cell migration during viral infection: role of adhesion molecules and chemokines. Immunol Lett 85: 119-127.

Vaday GG, Franitza S, Schor H, Hecht I, Brill A, Cahalon L, Hershkoviz R, Lider O 2001. Combinatorial signals by inflammatory cytokines and chemokines mediate leukocyte interactions with extracellular matrix. J Leukoc Biol 69: 885892.

Yusuf-Makagiansar H, Anderson ME, Yakovleva TV, Murray JS, Siahaan TJ 2002. Inhibition of LFA-1/ICAM-1 and VLA-4/VCAM-1 as a therapeutic approach to inflammation and autoimmune diseases. Med Res Rev 22: 146-167.

Wang Y, Afanasyeva M, Hill SL, Rose NR 1999. Characterization of murine autoimmune myocarditis induced by self and foreign cardiac myosin. Autoimmunity 31: 151-62. 